\title{
A Multi-Cylinder Airflow \& Residual Gas Estimation Tool Applied to a Vehicle Demonstrator
}

\author{
Mark Subramaniam, Henning Kleeberg, Anamitra Bhattacharyya, Nick Chomic and \\ Dean Tomazic \\ FEV, Inc.
}

Copyright $@ 2010$ SAE International

\section{ABSTRACT}

In a gasoline engine, the cycle-by-cycle fresh trapped charge, and corresponding unswept residual gas fraction (RGF) are critical parameters of interest for maintaining the desired air-fuel ratio (AFR). Accurate fueling is a key precursor to improved engine fuel economy, and reduced engine out emissions. Asymmetric flow paths to cylinders in certain engines can cause differences in the gas exchange process, which in turn cause imbalances in trapped fresh charge and RGF. Variable cam timing (VCT) can make the gas exchange process even more complex. Due to the reasons stated above, simplified models can result in significant estimation errors for fresh trapped charge and RGF if they are not gas dynamics-based or detailed enough to handle features such as variable valve timing, duration, or lift. In this paper, a new air flow and RGF measurement tool is introduced. The tool is a combination of 1-D gas dynamics modeling and imposed, measured dynamic pressure signals in the intake and exhaust manifolds. With this method, the components to be modeled in the gas exchange system are reduced to a minimum, making it possible to model the gas exchange process with adequate detail and still maintain reasonable tool execution time. In this approach, the accuracy of the air flow and RGF estimation are not influenced by the location of pressure transducers and it is possible to "track" EGR flow from the exhaust to the intake system. The tool is demonstrated on a 4-cylinder gasoline engine powered vehicle with dual intake and exhaust cam phasing. Predictions from the tool are compared to AFR and other real-time signals measured during a variety of different real-world transient drive cycles. The instantaneous fresh trapped charge, RGF across all cylinders, as well as the influence of VCT actuation is discussed.

\section{INTRODUCTION}

Understanding engine breathing has long been a focus within the powertrain community. Engine breathing is well understood and measured very accurately under steady state operation. The picture can be quite different under transient operation, where filling and emptying effects as well as the response attributes of sub-systems come into play. It is therefore quite valuable to have a tool that accurately estimates the amount of trapped fresh charge in any particular cylinder on a cycle-by-cycle basis. Such a tool should take into account all wave dynamics and account for valve opening and closing events, as well as represent in-cylinder thermodynamics to a sufficient degree. In engines featuring variable valvetrains, continuous variation in cam phasing needs to be accounted for as well. In the present study a fast-acting engine breathing tool is upgraded to multi-cylinder capability from its previous manifestation which featured single-cylinder capability only [1]. The tool is also upgraded to allow processing of up to 15,000 cycles of engine data, enabling residual gas and fresh charge

Page 1 of 21 
estimates for legislation-specific drive cycles, e.g. FTP 75 drive cycle. The goal is to understand differences between measured air flow values that are reported by the electronic control unit (ECU), and those calculated by the tool. Based on this understanding it will be possible to improve the fuel control calibration of the engine during transients by reducing brief moments of rich or lean operation. Clearly then, the long term goal would be improved fuel consumption, emissions, and driveability. The current version of the tool also features upgrades that filter noisy pressure indication data, and account for sensor response delays. A sophisticated data synchronization and merging algorithm is at the center of the process.

\section{MAIN}

\section{VEHICLE SETUP AND INSTRUMENTATION}

In order to assess the RGF tool from a transient perspective, a suitable 4 cylinder engine was selected. Selection of a 4 cylinder engine over a 6 or 8 cylinder engine decreased the number of sensors, and the complexity of the setup. The selected four-cylinder engine features port fuel injection in combination with dual independent cam phasing. This influence of exhaust gas dynamic is prevalent in this application and will allow the tool to showcase its capabilities and benefits.

\section{$\underline{\text { RGF Tool Parameter Input Requirements and Equipment }}$}

The RGF tool input requirements are:

- Dynamic pressure measurements in the intake and exhaust ports (with an option to utilize cylinder pressure measurements)

- Fast responding temperature measurements at each dynamic pressure location

- Timing of valve opening and closing events (if variable valve timing is used, the phase shift needs to be known as well)

- Fuel mass flow rate inferred from available ECU fuel injection information

All the pressures, temperatures, and valve events that needed to be recorded were measured by an FEV-CAS data acquisition system. All of these parameters were collected in the crank angle degree domain $\left({ }^{\circ} \mathrm{CA}\right)$. A $1^{\circ} \mathrm{CA}$ shaft encoder was used in combination with the FEV-CAS data acquisition system to record the high resolution engine data.

The FEV-CAS system consisted of 16 high speed channels capable of capturing data in up to $0.1^{\circ} \mathrm{CA}$ increments with the appropriate equipment. The unit included 8 lower resolution analog channels that logged measurements every engine cycle, or every 2 crankshaft revolutions. 


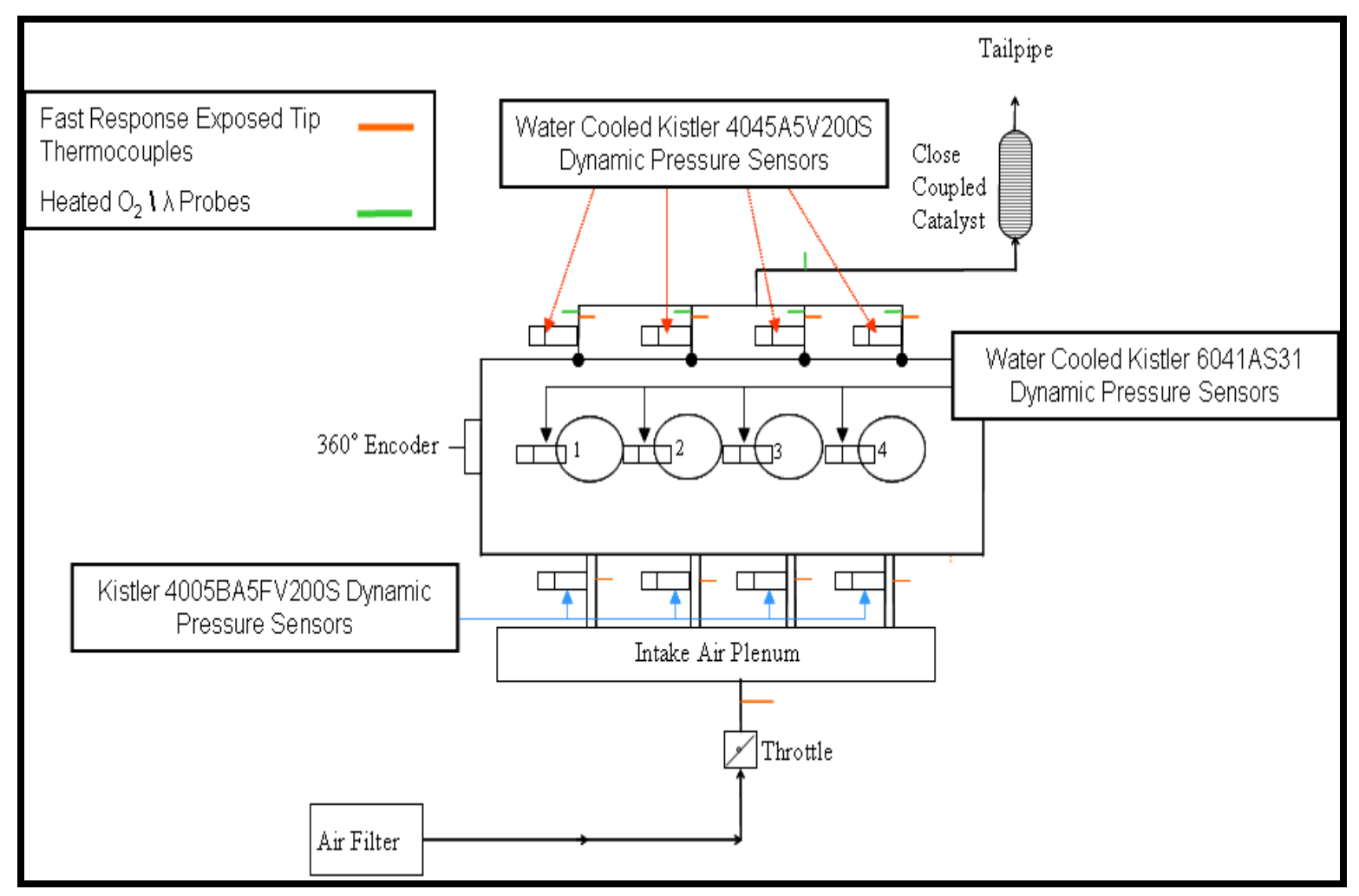

Figure 1: Block Diagram of Pressure and Temperature Locations in Test Engine

Dynamic Pressures and Fast Response Temperature Measurements

In each intake and exhaust port a separate sensor was installed to monitor the respective cylinders dynamic pressure. Dynamic pressure measurements were made with Kistler piezo-resistive sensors. A block diagram displaying the sensor location is shown in FIGURE 1.

The temperature measurements in each port were made with exposed tip style thermocouples (TC), both T and $\mathrm{K}$ type thermocouples, $\mathrm{T}$ type for intake and $\mathrm{K}$ type for exhaust temperature measurements. The exposed tip style decreased the junction diameter and led to shorter response times for the temperature measurement. At each location where a dynamic pressure is measured, a TC was installed to get the temperature at that same location. These exposed tip style TC units were selected based on the fact that they offer the fastest possible transient response time for this testing application. 


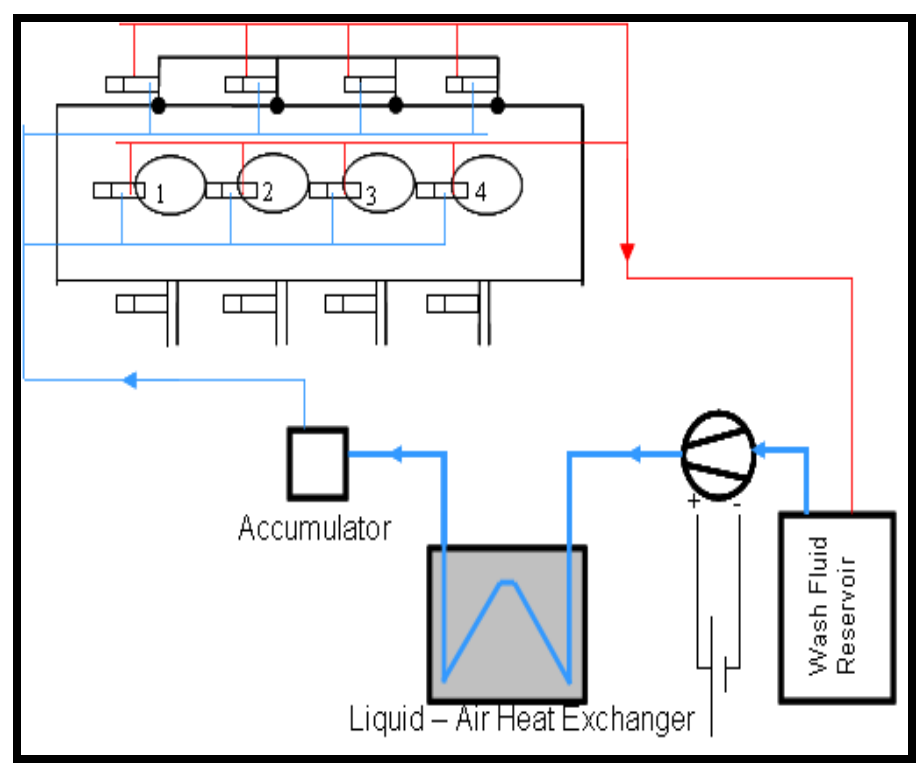

Figure 2: Block Diagram of Sensor Cooling Circuit Utilized in the Vehicle for Water Cooled Transducers

\section{Sensor Cooling System}

In order to equip the vehicle with the required cooled dynamic pressure sensors an additional cooling system was required. The exhaust and cylinder pressure sensors were all cooled transducers. The cooling system, shown in FIGURE 5, used the stock washer fluid reservoir as a cooling water tank, and a gear water pump intended for use in typical aquarium setups. The pump moved water from the reservoir through an air-to-water heat exchanger located in front of the stock engine coolant radiator. Once the water exited the heat exchanger it filled a small accumulator that distributed it to all the individual cooling lines for each transducer. The cooling water exits the transducers and returns to the reservoir. This cooling system was essential since the sensors were exposed to high temperature gases. This allowed sensor drift to be minimized.

Variable Valve Timing Measurement

The valve opening events were determined by measuring valve lift profiles. The selected engine utilized a dual variable cam phasing system as well. Both the exhaust and intake VVT wheel signals were therefore instrumented to monitor the phase shift of each valve lift profile.

\section{Fuel Mass Flow Measurement}

The fuel mass flow was obtained from the ECU estimation. The incorporation of ECU measured or estimated parameters were essential for the practical development of the tool for transient usage and for the assessment of the accuracy of the process itself.

\section{$\underline{\text { Vehicle ECU Measurements and Equipment }}$}

The following values were selected to be collected from the ECU via an ETAS-INCA 1000 system:

- Engine coolant temperature

- Manifold absolute pressure (MAP)

- Engine Speed

Page 4 of 21 
- Intake air temperature before the filter and at the intake manifold

- Intake and exhaust target phasing and the actual phasing

- ECU-predicted mass air flow

- Throttle position

- Spark advance

- Cylinder ID - firing event designator

- Synchronization signal

- Injected fuel mass

These above parameters were used as inputs for the RGF tool as well as to monitor the tool's performance in relation to the engine's operation.

Additionally, each cylinder's air/fuel ratio was measured with individual air/fuel ratio sensors in each exhaust runner to facilitate correlation and comparison. The sensors were of the wide-band variety, and had an approximate manufacturer specified response time of $150 \mathrm{~ms}$. The sensors are from NGK.

Using d-Space as an Independent Synchronization Source

The ETAS-INCA acquisition system recorded data in the time domain, while FEV-CAS data was recorded in the rotational crank angle domain. These two systems had to be aligned in order to utilize the data. This domain alignment was achieved with an additional d-Space rapid prototyping unit. The d-Space unit created a unique synchronization signal. The algorithm utilized an ECU signal designating individual cylinder firing events and output a repeating pattern every 196 cylinder firing events. More details of this signal will be explained in a later section of this paper.

Three Data Acquisition System Setup

The test vehicle housed three separate data acquisition systems. The three systems acted independent of each other and collected their own respective data. In FIGURE 6, the overall structure and interaction between all the systems is identified. The primary function of FEV-CAS was to collect all the pressure and temperature data, which are the main inputs into the RGF tool. The ETAS-INCA device collected comparative data from the engine ECU and also allowed for additional signals to be collected that did not need to be sampled at a high resolution as the CAS data. The d-Space unit acted as a third party synchronization device only. 


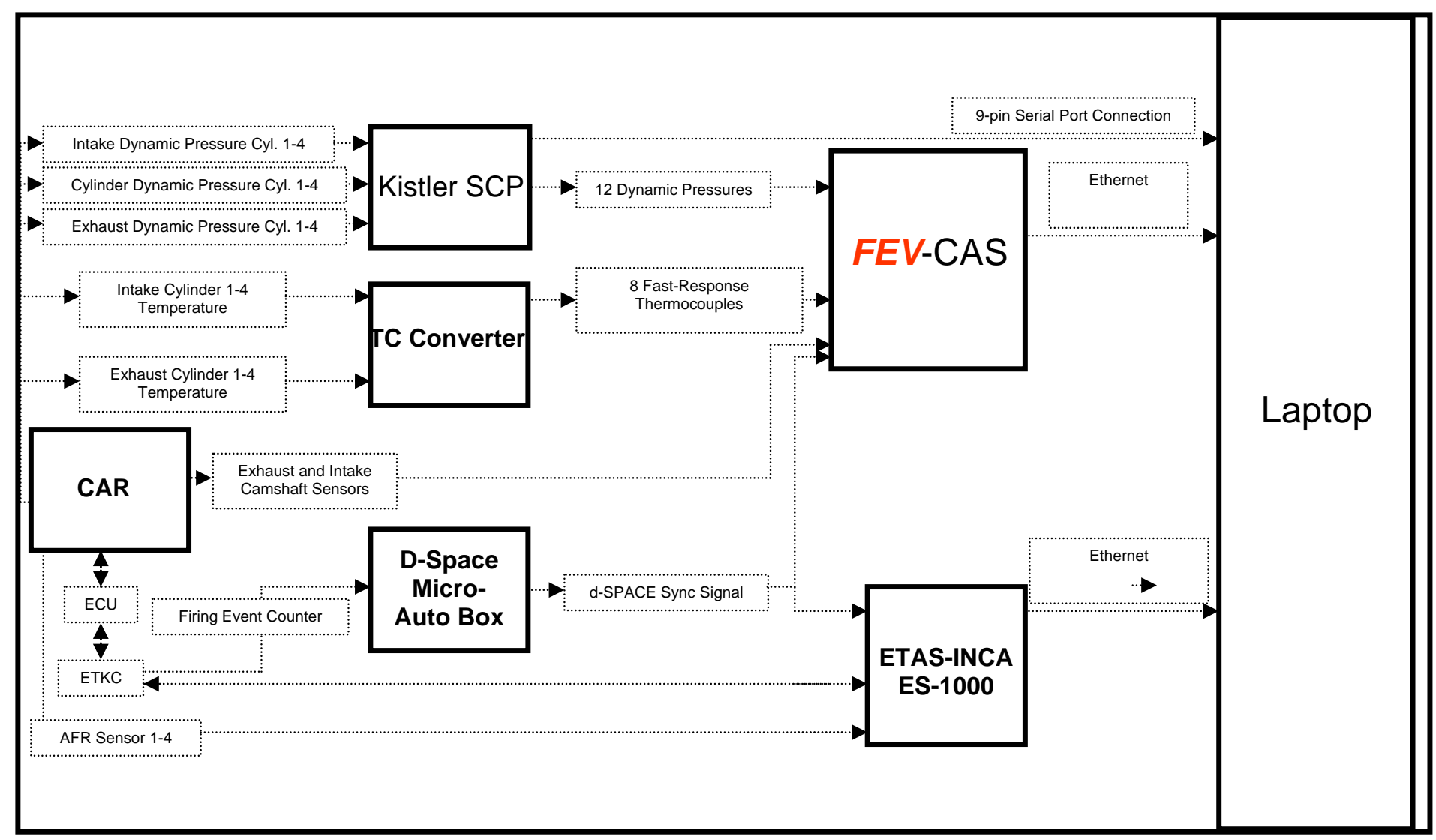

Figure 3: Flow Chart for Different Acquisition Systems Utilized with FEV RGF Tool

\section{DATA PROCESSING}

\section{$\underline{\text { Data Flow in the RGF Tool }}$}

Several data processing sub-steps are involved in the calculation of Residual Gas Fraction (RGF) and trapped air mass. The 1-D gas dynamics calculation part of the RGF tool is capable of processing up to 2,000 transient engine cycles at a time. The input data is usually acquired over a predefined vehicle drive cycle which translates to approximately 15,000 cycles of test data acquired with the use of several data acquisition systems. FEV-CAS acquires intake runner pressures, exhaust runner pressures and cylinder pressures for all four cylinders. Intake and exhaust cam phasing, as well as synchronization information is also obtained at every crank angle degree. 


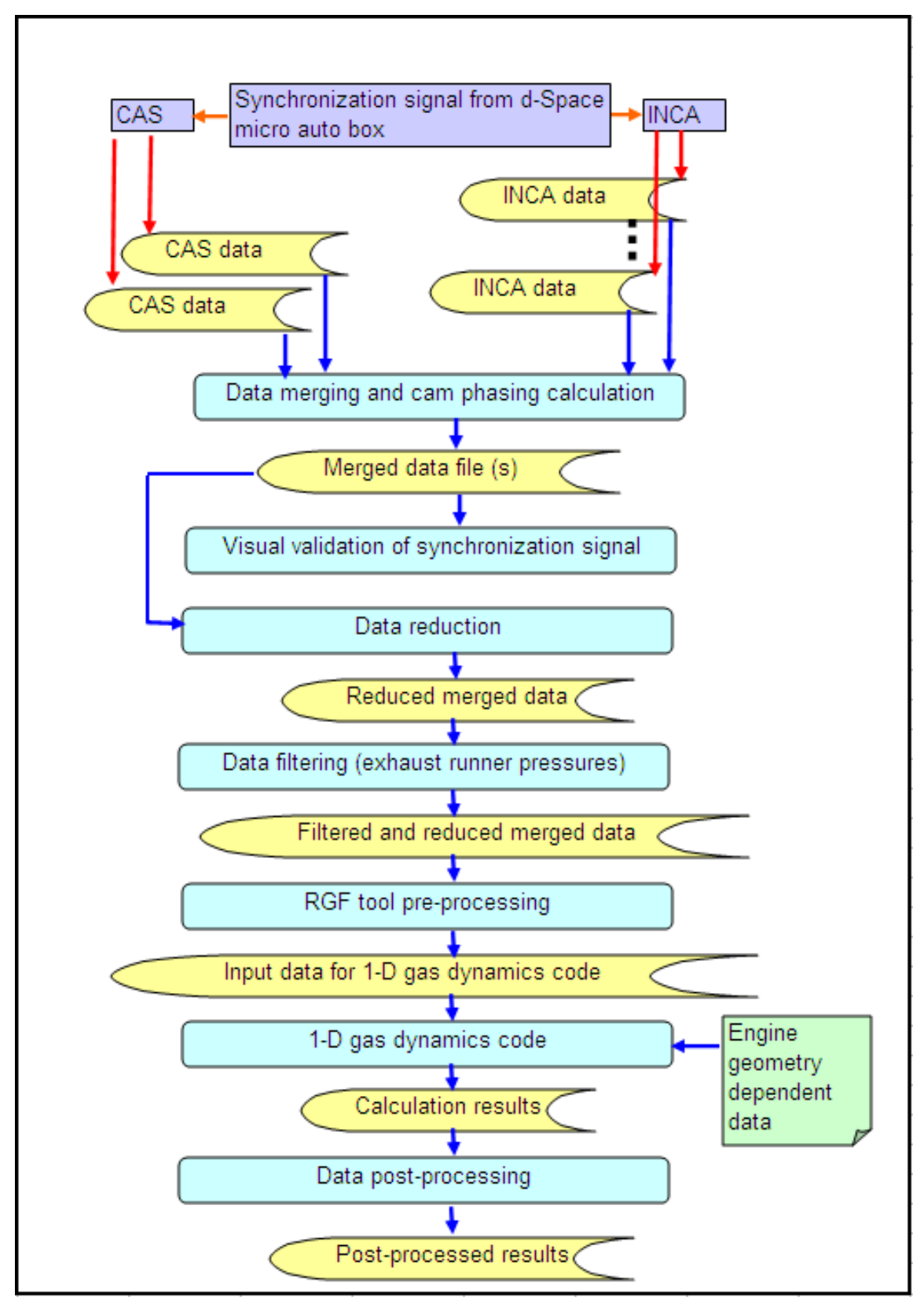

Figure 4: Data Flow in RGF Tool

FEV-CAS also acquires cycle averaged values for intake and exhaust runner temperatures for all cylinders, engine speed, and other key engine operating information. At the end of the data acquisition, two files are generated; one containing data at $1^{\circ} \mathrm{CA}$ resolution and the other containing cycle averaged data. Several parameters logged by the engine ECU are also exported to the RGF tool. After completion of data acquisition, with ETAS-INCA, these parameters are saved in the form of several files. A synchronization signal is used for merging of the data from the files generated in FEV-CAS and ETAS-INCA. The overview of the entire RGF calculation process is shown in FIGURE 7. These steps ensure that the test data is in the format required by the 1-D gas dynamics calculation and the output data is in the format required by the user. 
A d-Space micro auto box generates a unique signal which is fed into both the FEV-CAS and ETAS-INCA systems. D-Space uses a cylinder firing event signal from the ECU and generates a 1 millisecond wide Transistor Transistor Logic (TTL) pulse at TDC of cylinder 1, in a predefined order. The pattern emits its first pulse after four engine revolutions, the second pulse after five engine revolutions and this continues until a pulse is emitted after ten engine revolutions and subsequently the entire pattern is repeated again. This results in a pattern that repeats itself every 196 firings. This is shown in FIGURE 8. The determination of an engine revolution comes from the cylinder firing signal generated in the ECU. This signal displays 4 events per revolution since it is a 4 cylinder engine. Every time the cylinder ID pattern emits 4 pulses, a full engine revolution is considered to be complete.

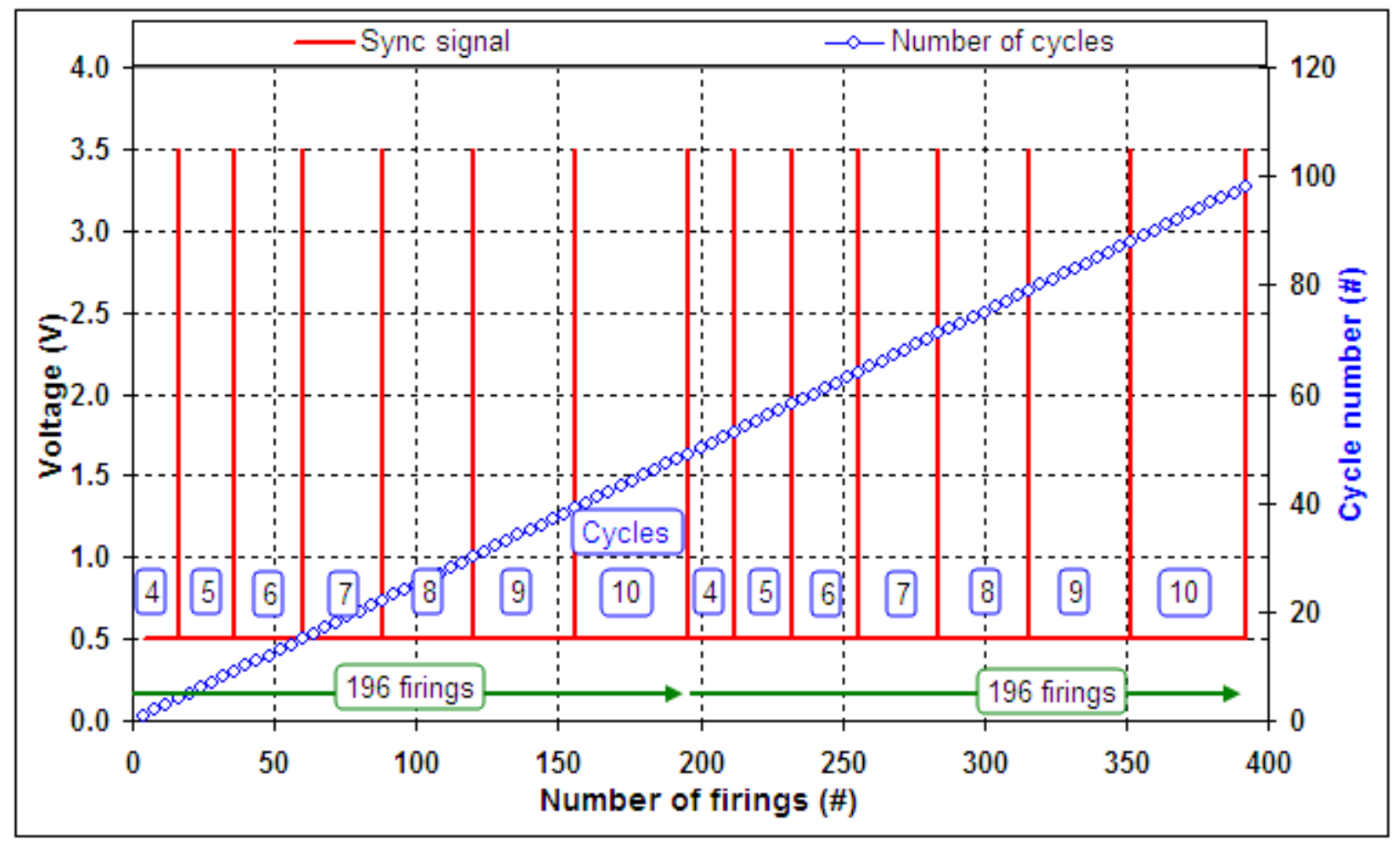

Figure 5: Synchronization Signal

\section{Merging of Data from Several Acquisition Systems}

The synchronization signal is used as a reference for merging data generated from the FEV-CAS and ETASINCA systems respectively. The data merging script is written in $\mathrm{C}$, with a Matlab-based graphical user interface. The merging process consists of three steps:

(1) Merging of the FEV-CAS data into a single file: The FEV-CAS data is acquired on a CA and cycle averaged basis (varies depending on signal measured). The single FEV-CAS data merged file features all data at $1^{\circ} \mathrm{CA}$ intervals. Cycle averaged values are repeated at every CA within any given cycle.

(2) Merging of the ETAS-INCA data into a single file: The ETAS-INCA generated files have different update rates. These files are merged into a single file with the highest resolution time stamp of the synchronization Page 8 of 21 
signal as the master time. The data with lower update rates have repeating values in the merged file containing all the ETAS-INCA data.

(3) Merging ETAS-INCA and FEV-CAS data into the final file: The unique pattern of the synchronization signal is searched for within the merged FEV-CAS and merged ETAS-INCA data files generated in the previous two steps. This provides the initial time difference between these two files. For every data row in the FEV-CAS data file, the ETAS-INCA data row with the closest time is located and matched up with the FEVCAS data row. The merged file contains all the FEV-CAS data and the ETAS-INCA data rows matched to the closest possible time.

Due to the large size of the input files, the merged files are usually divided into several smaller files, each containing a maximum of 2,000 cycles of data.

\section{$\underline{\text { Processing of VVT Signals }}$}

Calculations to determine individual intake and exhaust cam timing are performed while merging the FEV-CAS and ETAS-INCA data files. Both intake and exhaust cam signals contain four rising and four falling edges during one complete cycle. To determine the parked or default position of a particular cylinder, the code locates the falling edge of the intake cam signal closest to the intake valve opening of that cylinder. The corresponding CA value is the default intake cam timing for that cylinder. During the drive cycle, the same process is repeated, and cam phasing is indicated by the departure in the location of the falling edge from its default value. A similar approach is used to determine exhaust cam positions for all four cylinders. This process is illustrated in FIGURE 9.

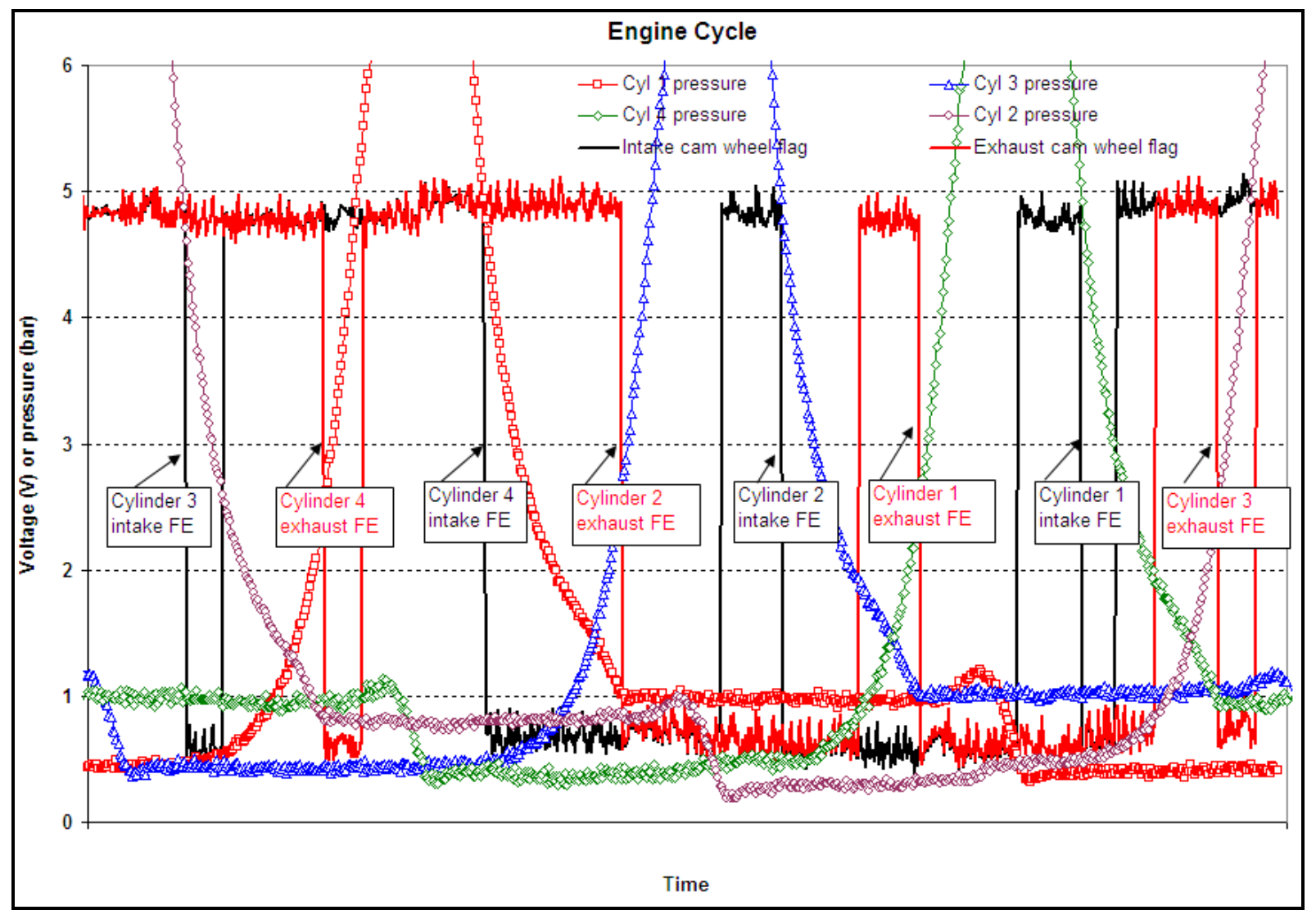

Figure 6: Cam Signals and Cylinder Pressures

Page 9 of 21 
The Matlab user interface is used for the validation of the data merging process. The tool is setup to load 50,000 lines/69 cycles of merged data at a time and plot the synchronization signals logged by FEV-CAS and ETASINCA. The user can verify whether the two synchronization signals match until the end of the merged file in steps of 50,000 lines. FIGURE 10 shows this visual validation step for 1 to 69 cycles of a merged file containing 15,000 cycles.

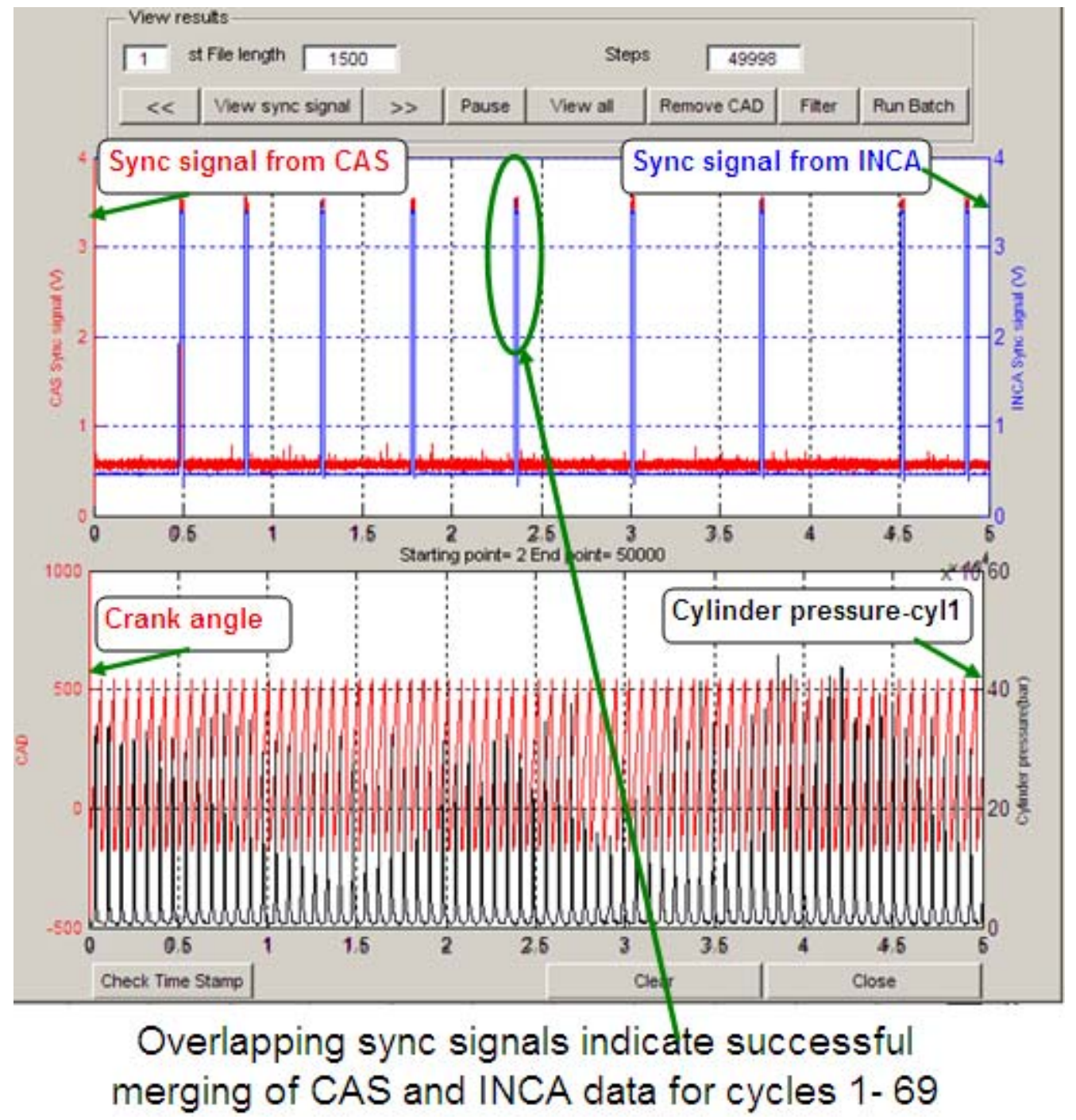

Figure 7: Visual Validation of Synchronization Process

\section{Data Reduction and Filtering}

The saved data from FEV-CAS contains CA values for each of the acquired parameters recorded at $1^{\circ} \mathrm{CA}$ resolution. After phasing the intake runner pressures, cylinder pressures and exhaust runner pressures, the additional CA columns are deleted to reduce the file size.

The exhaust runner pressures contain fluctuations which are filtered out using a 40th order filter. 


\section{RGF TOOL}

\section{$\underline{\text { General Description }}$}

The RGF tool solver incorporates 1-D gas dynamics in the manifold system and a 0-dimensional in-cylinder process. The governing equations for gas dynamics in a pipe/cylinder system as well as solution schemes utilized in the solver are discussed in detail in reference [1][2].

The 1-D gas dynamics calculation involves the intake runner, stretches across cylinder ports and extends out to the exhaust runner. Although the tool can be used to model the entire engine gas exchange system by specifying pipe dimensions (length, diameter) and connections (junctions), it is not practical for applications with large drive cycle-specific data sets simply because it is too computationally intensive. Instead, the tool only models the section between the intake and exhaust dynamic pressure transducers. The RGF tool takes in the measured pressure traces and imposes them as boundary conditions for the modeled runners. This allows representation of the system upstream of the intake and downstream of the exhaust through the imposed pressure traces.

\section{User Interface}

The user interface of the RGF tool is written in the Microsoft Excel environment. The interface code is written in Visual Basic with the use of macros for preparing data for the 1-D gas dynamics calculation. The first step is the data pre-processing where a procedure, written in FORTRAN, is used to select and sort the merged and filtered input data in a predefined format to be used for the subsequent calculation. The Visual Basic interface also generates text files containing the engine geometry dependent data. Using the data from the text files and the engine operation dependent data file generated from the pre-processing step, the 1-D gas dynamics code (coded in FORTRAN) calculates several cycle averaged parameters including trapped fresh air mass and RGF.

\section{$\underline{\text { Inputs and Outputs }}$}

The 1-D gas dynamics code receives the following engine operation dependent data input at $1^{\circ} \mathrm{CA}$ resolution:

Engine speed, engine fuel flow, spark timing, intake runner pressures, filtered exhaust runner pressures, cylinder pressures for all cylinders, processed cam timing for intake and exhaust cams, intake and exhaust runner temperatures for all the cylinders.

The required engine geometry dependent data is entered only once into the model (unless any hardware change is incorporated). These data include:

- $\quad$ Engine dimensions: bore, stroke, connecting rod length, compression ratio.

- $\quad$ Valve lifts versus crank angle for both intake and exhaust valves.

- $\quad$ Intake and exhaust port flow coefficients.

- Intake and exhaust dimensions (length, diameter and diameter versus length profile) from the valve to the location of pressure measurements.

The code calculates the following parameters for each engine cycle and for each cylinder:

IMEP, PMEP, cylinder volume, trapped mass, trapped fresh charge, burnt gas and RGF. 
The three governing equations of the gas dynamics process in a manifold, namely conservation of mass flow rate, enthalpy and momentum, were solved in discrete time and space (along pipe length) utilizing a finite difference scheme [1][2]. The in-cylinder process is treated 0-dimensionally, i.e. in-cylinder parameters were assumed to only change with time but remain homogenous with space. The gas mass trapped in-cylinder is determined from solving the flow equations across the ports, taking into account the instantaneous pressure at ports, in-cylinder and effective port flow area determined from known (input data) valve lift/CA curves and port flow coefficients. The initial version of the solver does not use the measured cylinder pressures and is called the 2-Pressure (2P) approach. In this approach, in-cylinder pressures and temperatures are solved from in-cylinder energy and mass conservation equations, taking into account the enthalpy of gas passing through the ports, the mixing of fresh charge with residual gas (at the same pressure but different temperature and with different gas properties), and heat transfer between the gas and cylinder walls. The in-cylinder heat transfer coefficient is calculated with the widely used Woschni equation, with mean cylinder wall temperature as input data. The tool is subsequently modified to include the measured in cylinder pressures for all the four cylinders for in-cylinder calculations from IVC to EVO and is called the 3-Pressure (3P) approach. This approach results in closer approximation of in cylinder processes to test data and eliminates the need for tuning of the tool. FIGURE 11 shows the comparison between these two approaches during a transient engine run consisting of 500 cycles.

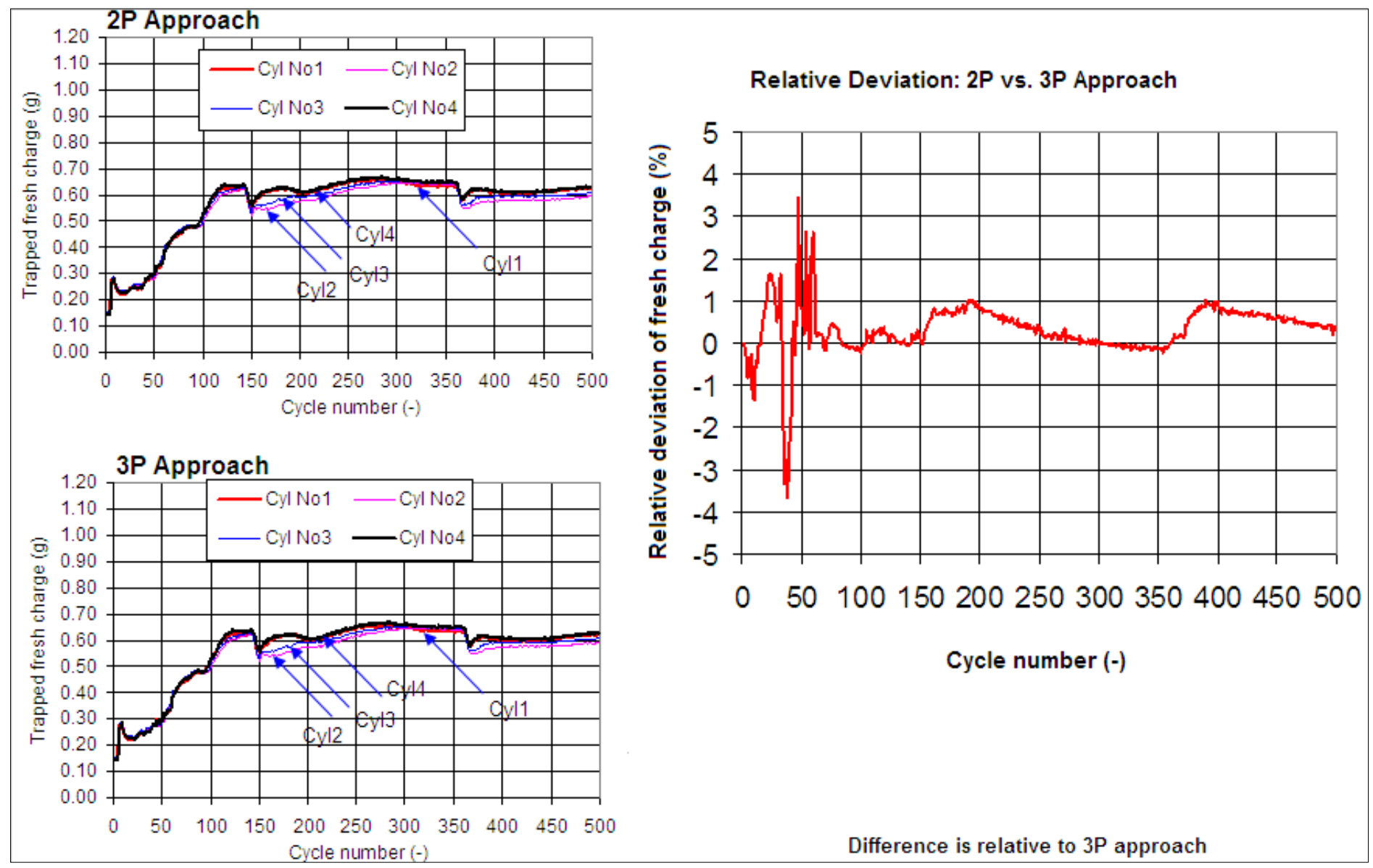

Figure 8: Comparison of 2P and 3P Approach

Page 12 of 21 
The approach of the RGF tool is similar to the Three Pressure Analysis (TPA) tool available in GT-Power. One difference is in that the TPA tool features a finite volume solver while the RGF tool features a finite difference solver. For internal combustion gas dynamics problems, the authors do not anticipate any noteworthy difference in predictions to be attributable to the difference is solvers. Differences are more likely due to differences in handling of in-cylinder phenomena such as combustion and heat transfer, as well as corrections to measured quantities under transient conditions (compensation of the response time associated with a transient temperature measurement for instance).

The TPA tool is not structured to analyze transient runs, i.e. the maximum number of data lines it can load is $20,000\left(<30\right.$ cycles at $1^{\circ}$ CA resolution).

Steady state test bench data from a four cylinder turbocharged gasoline engine is used for validation and comparison of the RGF tool. Identical test data is also applied to a GT-Power four cylinder TPA model for purposes of comparison. Air/fuel mass flow rate through the engine, pressure traces in proximity to the intake and exhaust ports as well as in cylinder, steady state pressure and temperature are measured at several locations on the engine. This data is used as input data to both the RGF and TPA tools, and also for comparison to predicted results. Since no direct RGF measurement is available from the vehicle measurements, the output of the RGF tool is compared to results from the TPA tools at 20 different engine operating points. FIGURE 12 shows the mass flow rate comparison between measured data, the TPA tool results, and the RGF tool results. FIGURE 13 shows the comparison of calculated RGF values between RGF tool and the TPA tool for the same series of operating points.

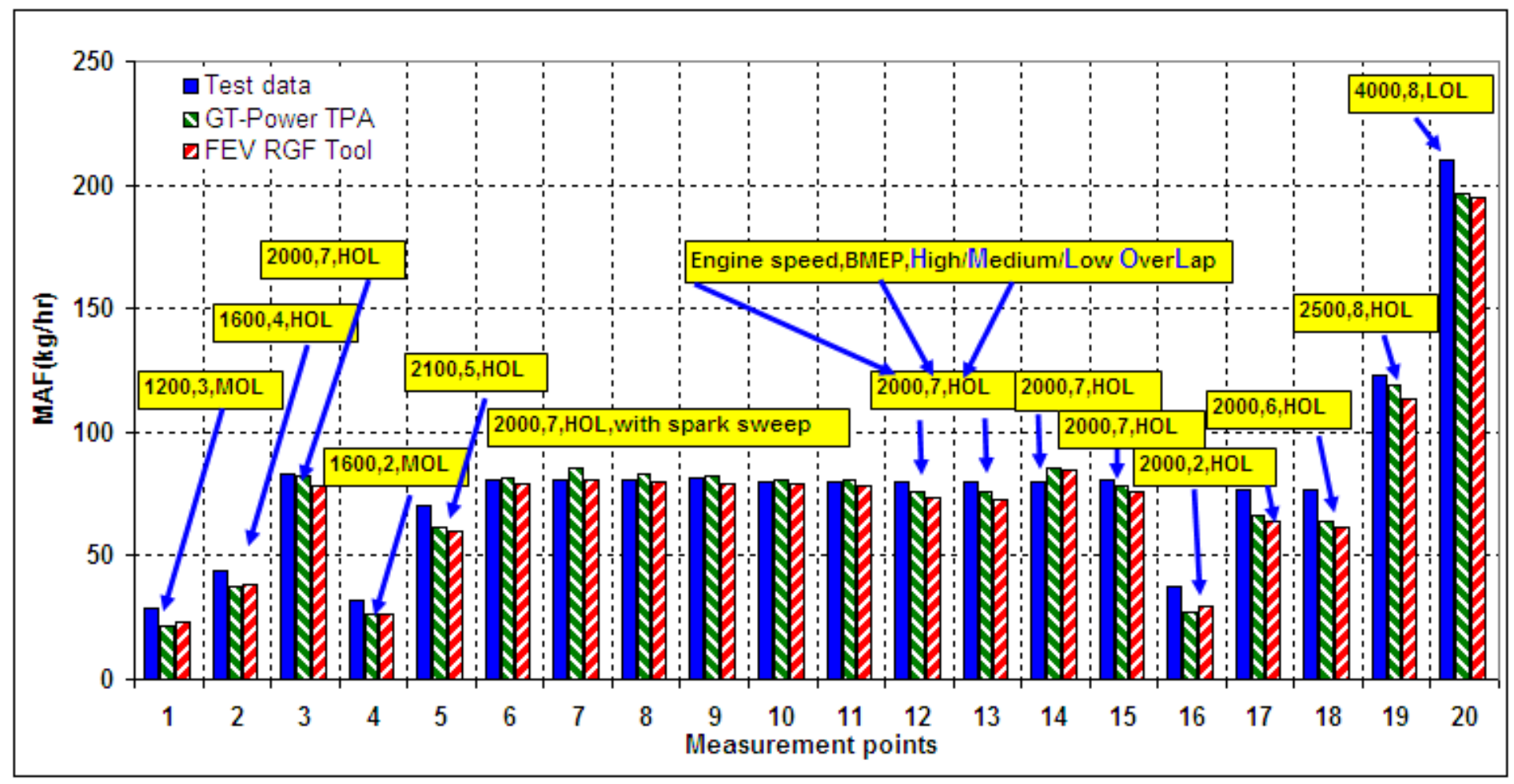

Figure 9: Fresh Air Comparison among Test Data, GT-Power TPA and RGF Tool

It can be seen that overall the TPA and RGF tool results seem to correlate better to one another then to the test data. While there seems to be no clear trend as to when the analytically estimated mass flows (both tools) Page 13 of 21 
correlate well to test data, it can be see that disagreement between TPA tool estimates and RGF tool estimates are most frequently seen at high cam overlap. The latter is true for both high and low flow operating points.

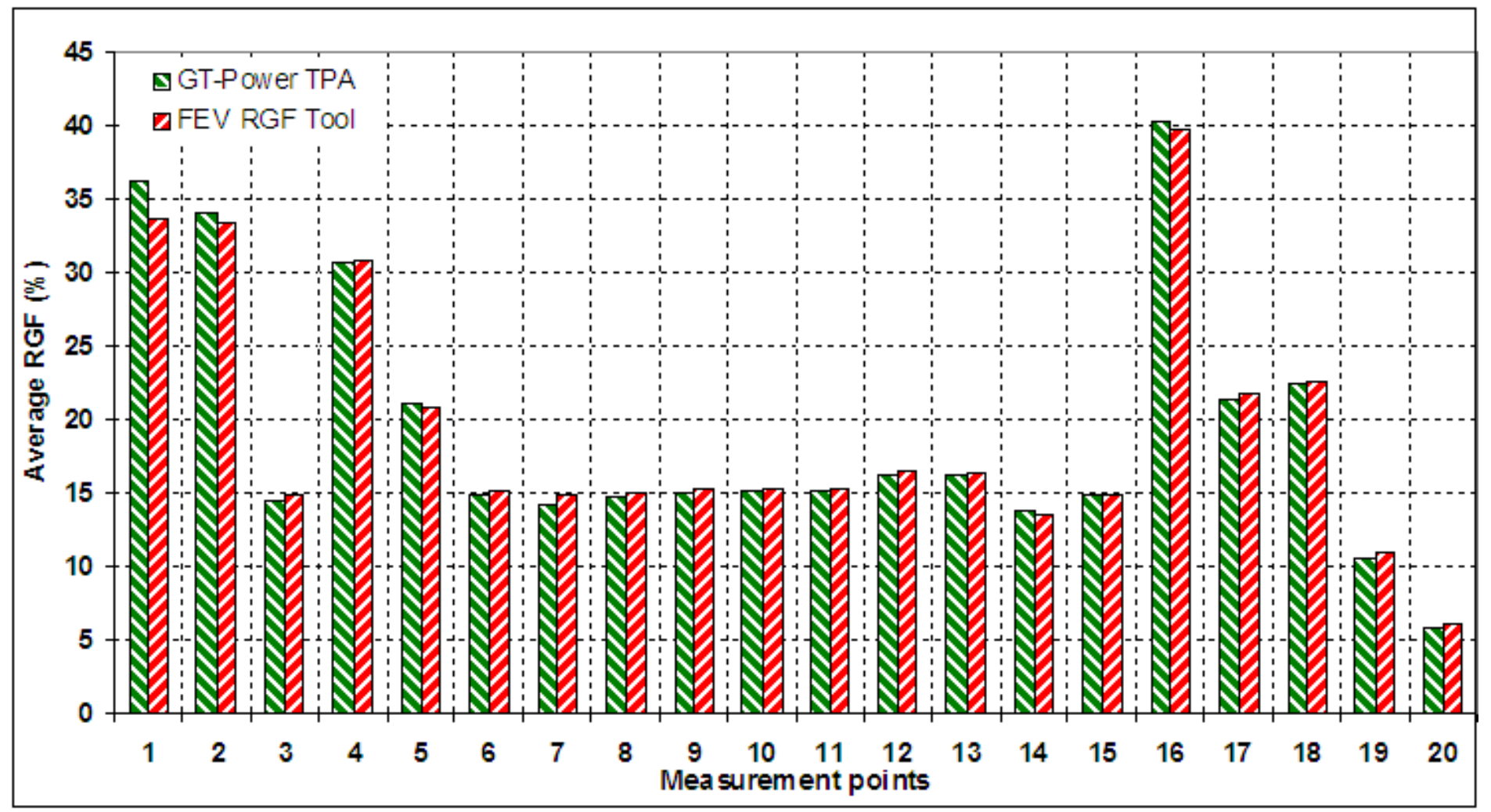

Figure 10: RGF Comparison between GT-Power TPA and RGF Tool

$\underline{\text { Processor Requirements and Limitations }}$

The data merging and RGF calculations are performed using a notebook computer having a $1.86 \mathrm{GHz}$ processor and 2 GB RAM. The most time consuming process is the filtering of the exhaust pressure traces which are performed in the Matlab environment. The remainder of the data merging and calculations are performed in $\mathrm{C}$ and FORTRAN and are much faster in comparison to the Matlab-based step . Due to large amount of data involved, the entire process takes several hours to complete.

For a typical test run consisting of 15,000 cycles, the FEV-CAS system records around 4 GB of data with $1^{0}$ CA resolution. The synchronization signal file, recorded at 20 microsecond intervals by ETAS-INCA, requires 2.5 GB of disk space. The merged file containing all the FEV-CAS and ETAS-INCA data requires disk space of approximately 1 GB for each 1500 cycles. At least 100 GB of free disk space is therefore required to process every 15,000 cycles.

The 1-D gas dynamics calculation written in FORTRAN can handle up to 2,000 cycles of input data. Therefore the merged input data is divided into smaller files if the total number of cycles exceeds 2,000.

The tool is very sensitive to measured intake and exhaust runner pressures, valve lift profiles and port flow coefficients. High test data accuracy is required for meaningful results to be produced.

Page 14 of 21 
Real time processing will require significant hardware and software upgrades due to the large amount of data and the number of processing steps involved. The software upgrade would require all the pre-processing and data sorting, execution of the RGF calculation, and post processing to be executed sequentially in the same environment, with no importing and exporting from files. The hardware upgrade would involve the creation of an interface package that pulls signals directly from the various data acquisition systems, and combines them into a single input packet that simplifies the pre-processing described in the software upgrade above. This is key as the pre-processing step can 'make or break' the real-time capability of the tool.

\section{ANALYSIS AND RESULTS}

\section{Correlation to ECU Measured Airflow}

The RGF tool is used to process transient engine operation data consisting of 15,000 cycles and the trapped air mass calculated by the tool is compared with the air mass signal received from the ECU (total of all four cylinders). FIGURE 14 shows these two parameters during 1,500 cycles of transient engine operation. Also shown is the percentage difference between these two parameters during the same period. The plot shows up to 10 percent difference between air mass reported by the electronic control unit (ECU) and those calculated by the RGF tool. The engine speed, IMEP, and intake and exhaust cam timings during the same period are shown in FIGURE 15.

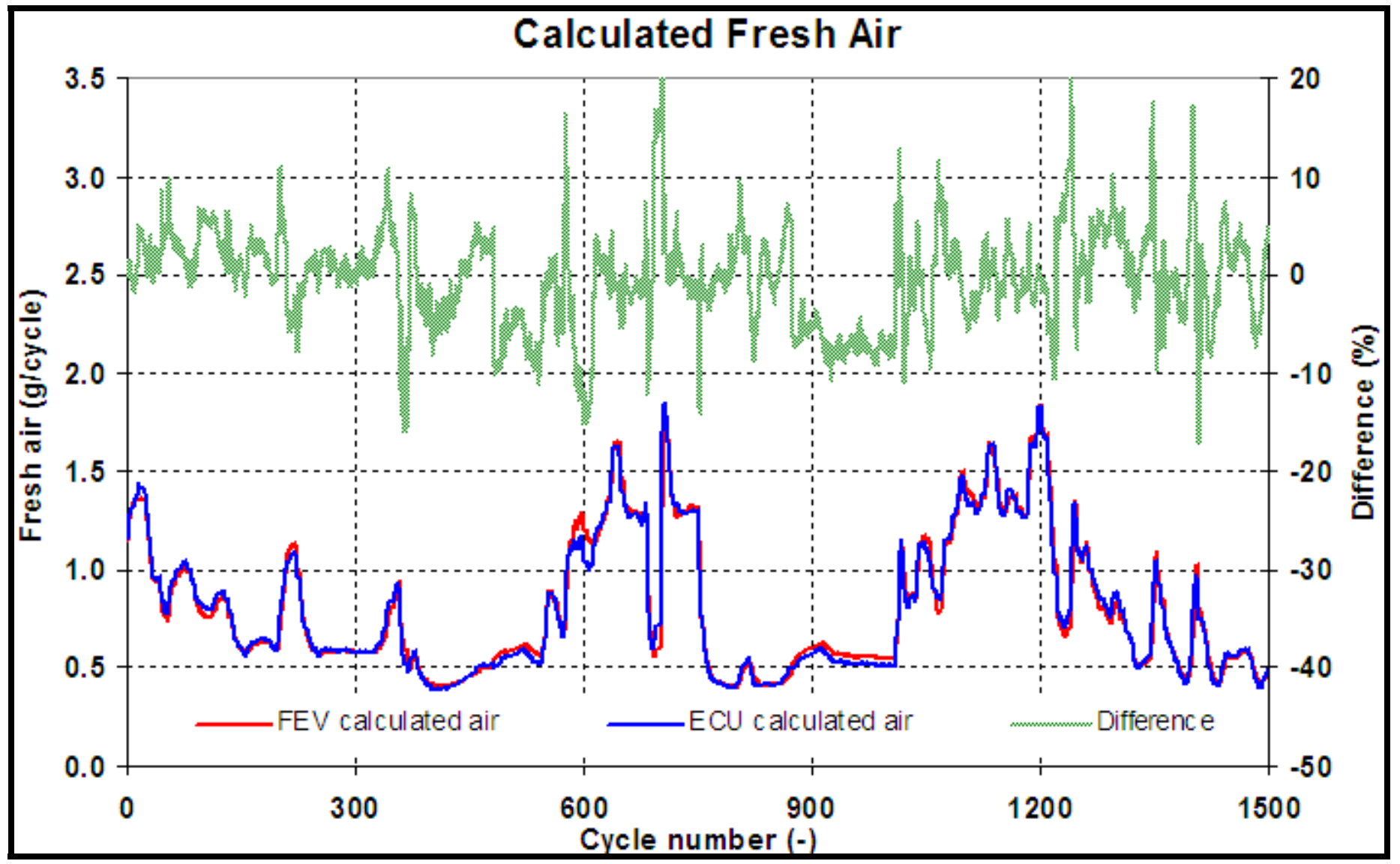

Figure 11: Comparison of Calculated Fresh Air to ECU data

Page 15 of 21 


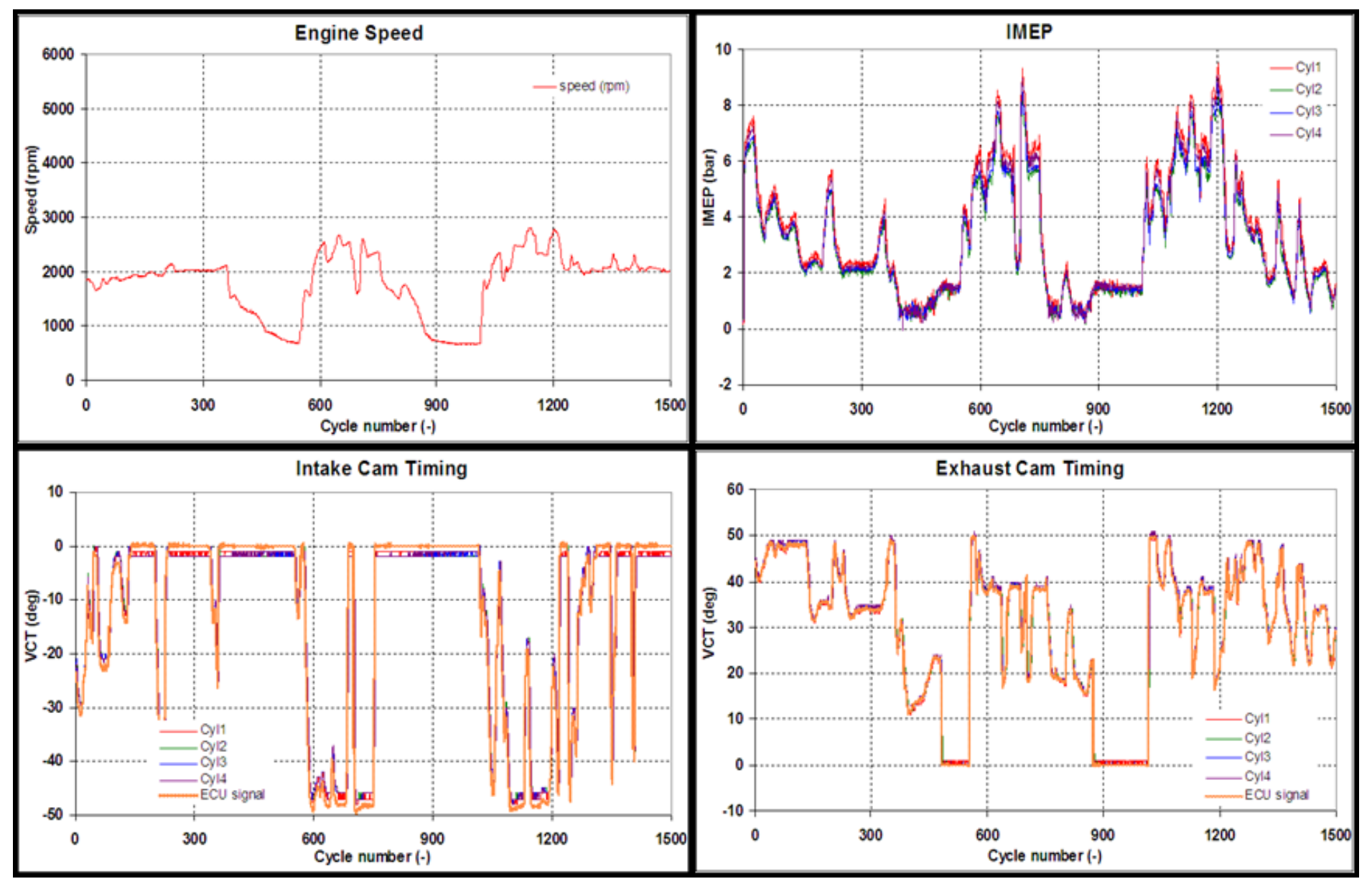

Figure 12: Engine Operating Parameters

\section{$\underline{\text { Pairing of Cylinders at High Flow }}$}

Under transient operation, strong manifold tuning effects are observed when either the engine speed, cam position, or the throttle position is changed. This causes deviations in the processed air flow and RGF results across all the cylinders. The engine under study has an exhaust manifold layout with paired runners for cylinders 1 and 2, and cylinders 3 and 4. FIGURE 16 shows that at high flow conditions, cylinders 2 and 3 have higher RGF than cylinders 1 and 4. The explanation for this difference between cylinder pairs can be found from analyzing data from cycle number 250. FIGURE 17 shows the engine speed, intake runner pressures, exhaust runner pressures and intake and exhaust cam phasing during cycle number 250. During the intake valve opening duration, cylinders 2 and 3 have higher exhaust back pressure than cylinders 1 and 4 . This difference results in the higher RGF and lower trapped air mass for cylinder pair 2 and 3 in comparison to cylinder pair 1 and 4. FIGURE 18 shows the intake runner, exhaust runner and cylinder pressures for all four cylinders. The black circles show that during IVO of cylinders 2 and 3, the exhaust pressures are higher in comparison to cylinders 1 and 4 (shown with red circles). Relatively higher pressures in the exhaust wave of cylinder 2 and 3 (shown with black circles) during the IVO of the respective cylinder is due to the EVO of the cylinders in the same manifold grouping. Due to high valve overlap during this operating condition, the higher exhaust pressure waves influence the intake pressures of cylinders 2 and 3. The lower pressures seen in the exhaust pressure wave at IVO of cylinder 1 and 4 is due to the exhaust blow down event occurring in the other section of the manifold at the time of the valve overlap. 
It can therefore be stated that increase of valve overlap at high engine loads leads to increased residuals in cylinders 2 and 3 due to the exhaust manifold layout, and corresponding gas dynamics. The RGF tool shows accurate prediction of this phenomenon.

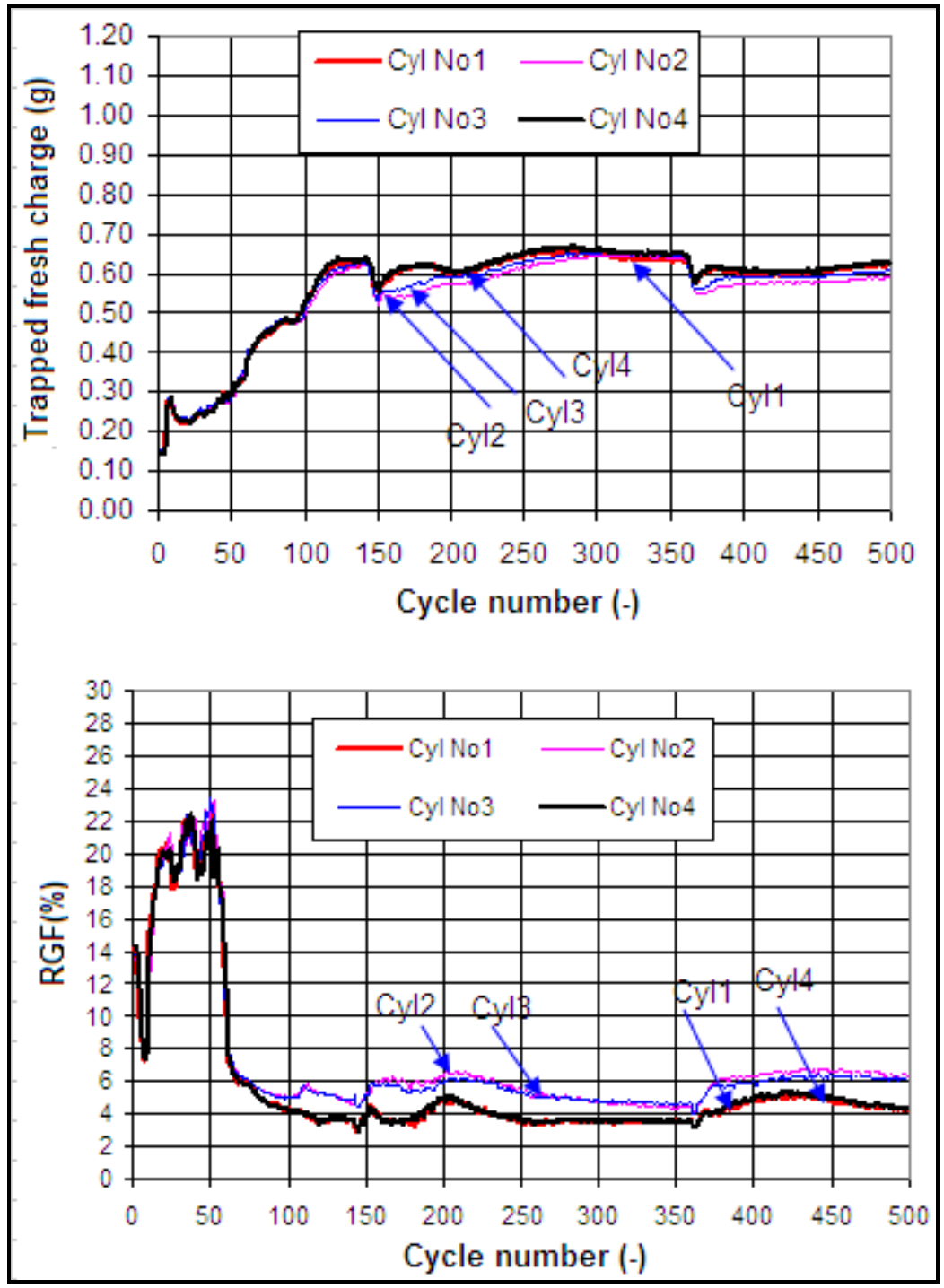

Figure 13: Paring of Fresh Air and RGF at High Flow 


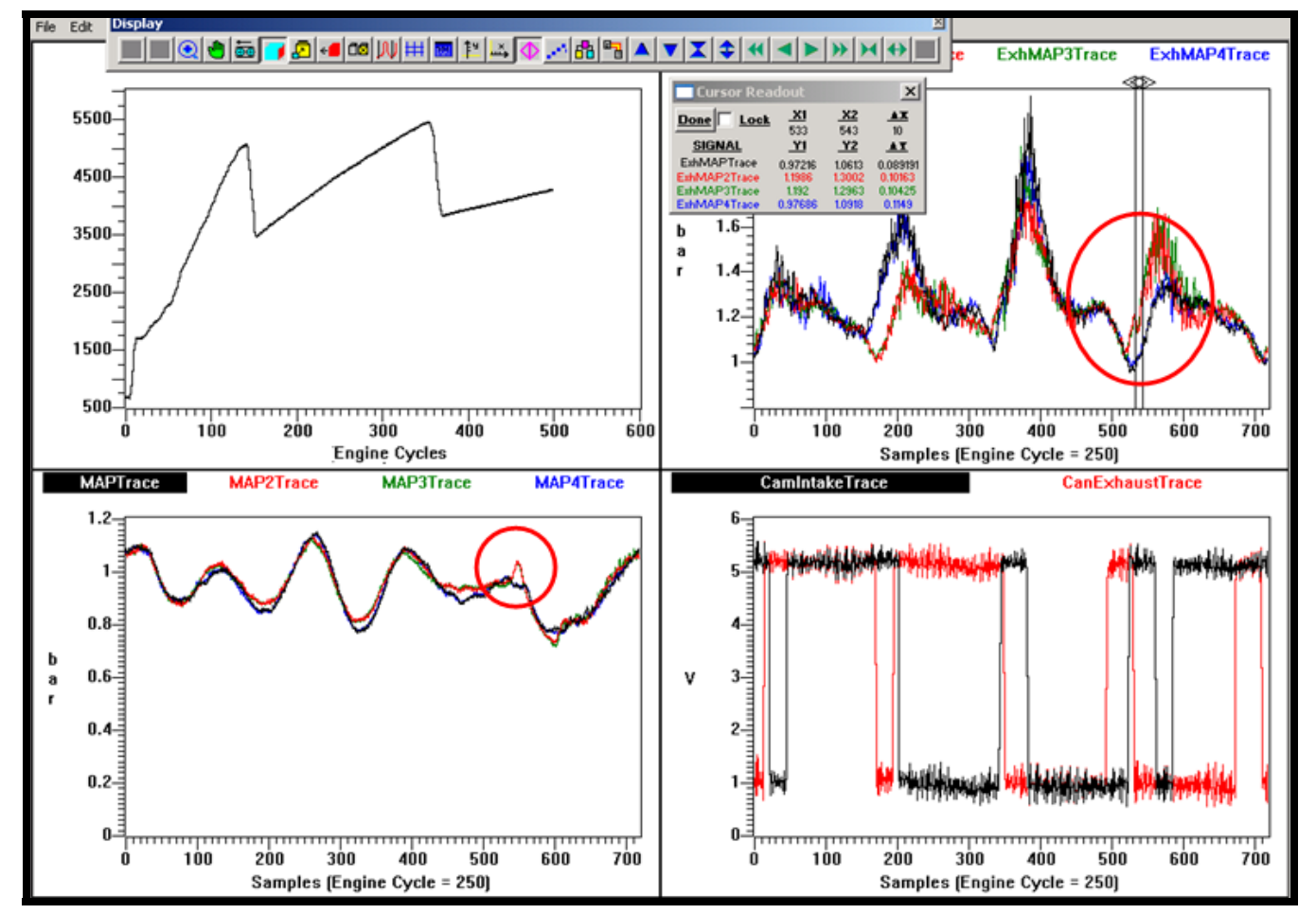

Figure 14: Engine Operating Parameters

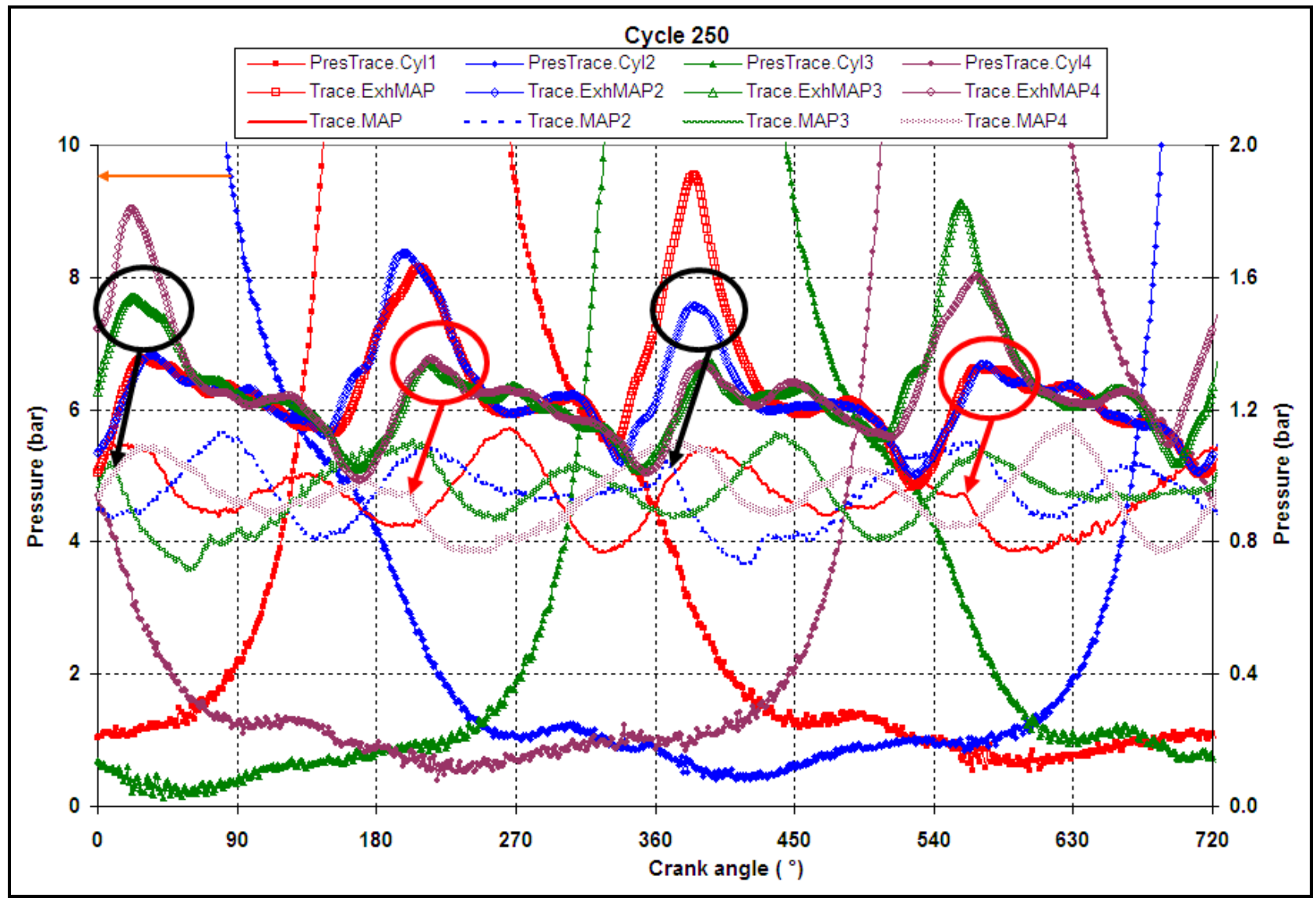

Figure 15: Intake Runner, Exhaust Runner and Cylinder Pressures

Page 18 of 21 
FIGURE 19 shows the measured air fuel ratios for all four cylinders, air fuel ratio calculated by the ECU and the calculated fresh charge over 1,500 cycles. The cylinder individual measured air fuel values are different from the target air fuel value from the engine ECU. The main area to make note of is the lean or rich spikes that occur when air flow is decreased or increased while the ECU commands a stoichiometric AFR. These excursions can be identified in transient situation with the RGF tool and the appropriate fueling can be applied to limit these events. The down side of having too many rich excursions is the unnecessary over fueling of the engine and resulting waste of fuel at part load since enrichment should not be necessary. The ability to correct lean excursions can help in keeping engine stability under control and keep the combustion thermal efficiency up. If the engine runs too lean during a transient situation, combustion stability and efficiency may decrease. The use of trapped air mass calculated by the RGF tool will allow more precise, individual cylinder control of engine fueling to improve engine response and reduce engine out emissions. This can be achieved by recalibration of the ECU with results from the RGF tool.

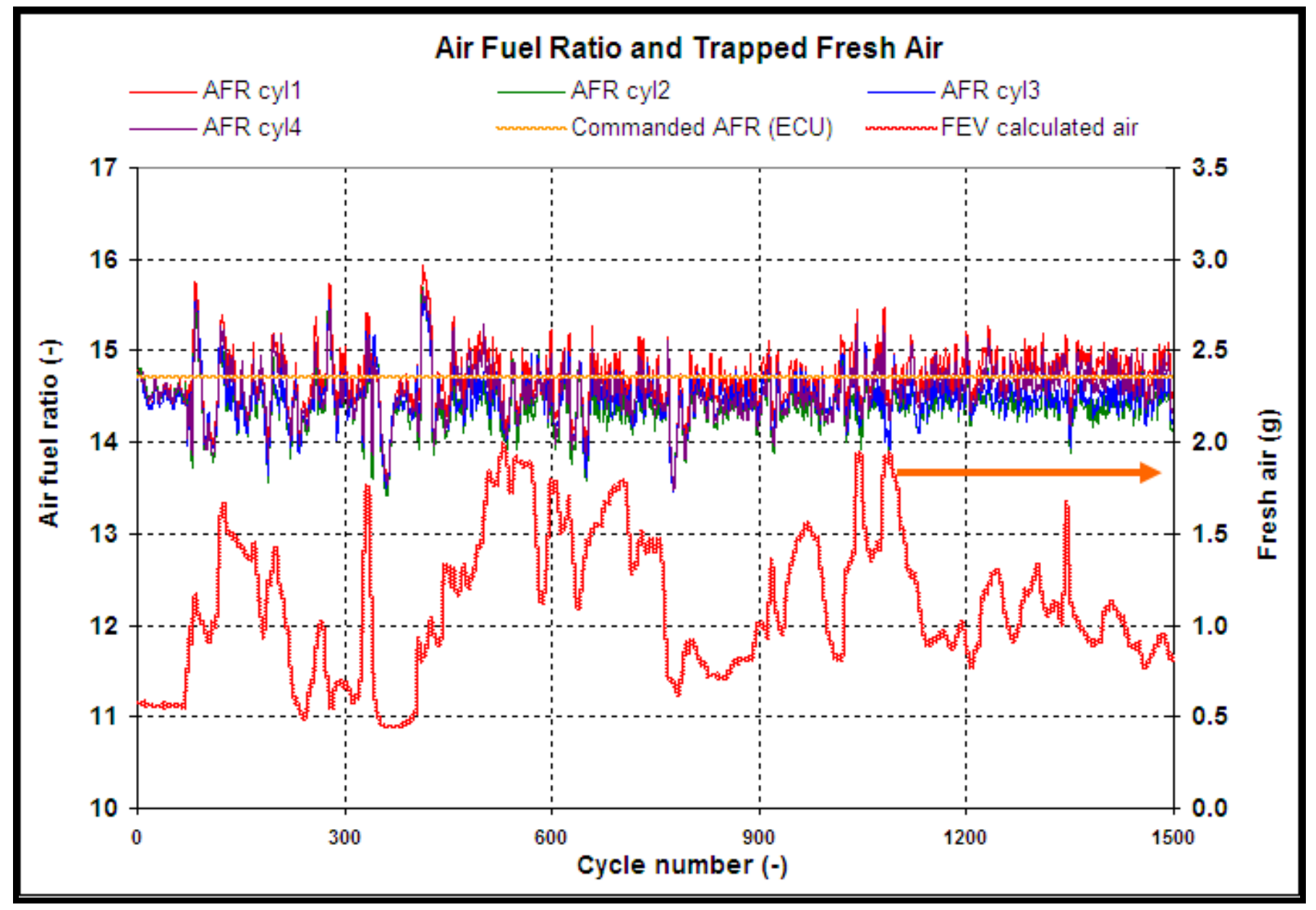

Figure 16: AFR and Calculated Fresh Air

Page 19 of 21 


\section{SUMMARY/CONCLUSIONS}

\section{HOW RESULTS CAN BE USED TO IMPROVE CALIBRATION}

The RGF tool allows improved air flow estimation capability during transient operation compared to air flow measurement devices. Errors in such measurement during transients often result in rich and lean excursions that are detrimental to the emissions and fuel economy of the application. With sufficient sampling and processing of data during a wide range of real world driving conditions, improved calibration constants and factors can be developed to reduce these air fuel ratio excursions. This can then allow more precise fueling and a subsequent improvement in efficiency, and emissions characteristics.

\section{OTHER BENEFITS}

The RGF tool can also provide accurate estimations of the quantity of residual or unswept burned gas that remains in the cylinder on a cycle-by-cycle basis. This can be very helpful in understanding and subsequently optimizing combustion system performance during idle, as well as high load, scavenged operation. This understanding is especially useful when significant amounts of intake and exhaust valve overlap come into play, which is the case with modern, cam-phased internal combustion engines.

\section{FUTURE WORK}

Planned future steps include further automation of the data management process to improve the handling of information and to increase processing efficiency. The tool will also be tailored to allow modular application to engines featuring from 1 to 8 cylinders.

\section{REFERENCES}

1. Jing Ping Liu, Henning Kleeberg, Dean Tomazic, Joseph A. Ciaravino and Amer A. Amer: “A Model for On-Line Monitoring of In-Cylinder Residual Gas Fraction(RGF) and Mass Flow rate in Gasoline Engines”, SAE 2006-01-0656

2. Jing Ping Liu, Norbert Schorn, Christof Schernus and Lixin Peng: "Comparison of Method of Characteristics with Finite Difference Methods on One-Dimensional Gas Flow in IC Engine Manifold”, SAE 960078

3. Richard Ford and Nick Collings, "Measurement of Residual Gas Fraction using a Fast Response NO Sensor”, SAE 1999-01-0208,1999

4. Terry Alger and Steven Wooldridge: "Measurement and Analysis of the Residual Gas Fraction in an SI Engine with Variable Cam Timing”, SAE 2004-01-1356

5. Jinyoung Jang, Kitae Yeom and Choongsik Bae: "Effects of Exhaust Throttling on Engine Performance and Residual Gas in an SI engine”,SAE 2004-01-2974

6. Paul J. Shayler, Lorne D. Winborn , Martin J. Hill and Derek Eade: “The Influence of Gas/Fuel Ratio on Combustion Stability and Misfire Limits of Spark- Ignition Engines”, SAE 2000-01-1208

7. Pascal Giansetti,Yann Chamaillard, Alain Charlet, Pascal Higelin and Sebastien Couet: "A Model for Residual Gas Fraction Prediction in Spark Ignition Engines”, SAE 2002-01-1735

8. Nicolò Cavina , Carlo Siviero and Rosanna Suglia: "Residual Gas Fraction Estimation: Application to a GDI Engine With Variable Valve Timing and EGR”, SAE 2004-01-2943

9. F. Schwarz and U. Spicher: "Determination of Residual Gas Fraction in IC Engines”, SAE 2003-01-3148

10. Uwe Koehler and Michael Bargende: "A Model for a Fast Prediction of the In-Cylinder Residual Gas Mass”, SAE 2004-01-3053

Page 20 of 21 


\section{CONTACT INFORMATION}

Mark Subramaniam

FEV, Inc.

subramaniam@fev-et.com

\section{DEFINITIONS/ABBREVIATIONS}

RGF Residual Gas Fraction

IVO Intake Valve Opening

IVC Intake Valve Closing

EVO Exhaust Valve Opening

VVT Variable Valve Timing

TPA Three Pressure Analysis

ECU Engine Control Unit

CAS Combustion Analysis System

${ }^{\circ} \mathrm{CA}$ Crank Angle

TTL Transistor Transistor Logic

VCT Variable Cam Timing

AFR Air-Fuel Ratio

ECU Electronic Control Unit,

FTP Federal Test Procedure

TC Thermocouples

MAP Manifold Absolute Pressure

.csv Comma Separated Values 